$1-1-2014$

\title{
Time-Dependent Mechanical Behavior of Proton Exchange Membrane Fuel Cell Electrodes
}

Zongwen Lu

University of Delaware

Michael H. Santare

University of Delaware

Anette M. Karlsson

Cleveland State University, a.karlsson@csuohio.edu

F. Colin Busby

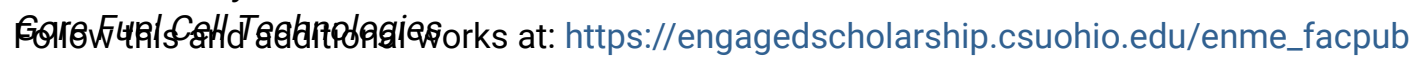

teantad she Mechanical Engineering Commons

Aera Fured\&alt Eesknglagisswork benefit you? Let us know!

Publisher's Statement

NOTICE: this is the author's version of a work that was accepted for publication in Journal of

Power Sources. Changes resulting from the publishing process, such as peer review, editing, corrections, structural formatting, and other quality control mechanisms may not be reflected in this document. Changes may have been made to this work since it was submitted for publication. A definitive version was subsequently published in Journal of Power Sources, 245, , (01-01-2014); 10.1016/j.jpowsour.2013.07.013

\section{Original Citation}

Lu, Z., Santare, M. H., Karlsson, A. M., 2014, "Time-Dependent Mechanical Behavior of Proton Exchange Membrane Fuel Cell Electrodes," Journal of Power Sources, 245, pp. 543-552.

This Article is brought to you for free and open access by the Mechanical Engineering Department at EngagedScholarship@CSU. It has been accepted for inclusion in Mechanical Engineering Faculty Publications by an authorized administrator of EngagedScholarship@CSU. For more information, please contact library.es@csuohio.edu. 


\title{
Time-dependent mechanical behavior of proton exchange membrane fuel cell electrodes
}

\author{
Zongwen Lu ${ }^{a}$, Michael H. Santare ${ }^{\mathrm{a}, *}$, Anette M. Karlsson ${ }^{\mathrm{b}}$, F. Colin Busby ${ }^{\mathrm{c}}$, Peter Walsh ${ }^{\mathrm{c}}$ \\ a Department of Mechanical Engineering, University of Delaware, Newark, DE 19716, USA \\ ${ }^{\mathrm{b}}$ Fenn College of Engineering. Cleveland State University, Cleveland, $\mathrm{OH} 44115, \mathrm{USA}$ \\ ${ }^{c}$ Gore Fuel Cell Technologies, Elkton, MD 21922, USA
}

\section{Introduction}

Numerous studies have been devoted to understanding the durability of proton exchange membrane fuel cells (PEMFCs) motivated by the desire to improve the lifetime of PEMFCs without unduly increasing cost or compromising performance [1-14]. Studies have shown that, although the electro-chemical interactions, transport losses and lack of ideal water management affect the durability of PEMFCs, chemical degradation and mechanical damage in the membrane electrode assembly (MEA) are major sources of failure [1-7]. Degradation and/or material loss in the MEA is commonly attributed to chemical attacks, but can also be significantly governed by the mechanical damage in the MEA [6]. Several forms of mechanical damage have been commonly

\footnotetext{
* Corresponding author. Tel.: +1 302831 2421; fax: +1 3028313619 . E-mail address: santare@udel.edu (M.H. Santare).

1 Nafion is a registered trademark of E.I. DuPont De Nemours \& Co.
}

observed in the MEA, such as through-the-thickness tears, pinholes in the membrane and delaminations between the membrane and electrodes [3-10]. It is commonly believed that the mechanical stresses, due to hygro-thermal changes in the MEA, are primarily responsible for the mechanical damage [9-14]. Therefore, investigating the hygro-thermal mechanical behavior of the MEA, which consists of the membrane and electrodes, is an important step toward understanding the fuel cell failure mechanisms and providing a science base for increasing the durability of PEMFCs.

In our previous experimental work, we have investigated the time-dependent mechanical behavior of a perfluorosulfonic acid (PFSA) membrane (Nafion ${ }^{\otimes} 211$ membrane) at selected strain rates for a range of temperatures and humidities [15]. The results showed that Young's modulus and the proportional limit stress increase as the strain rate increases, and decrease as the temperature or humidity increases. The results also showed that the mechanical response of Nafion 211 membrane is more sensitive to typical changes in strain rate or temperature than to typical changes in 


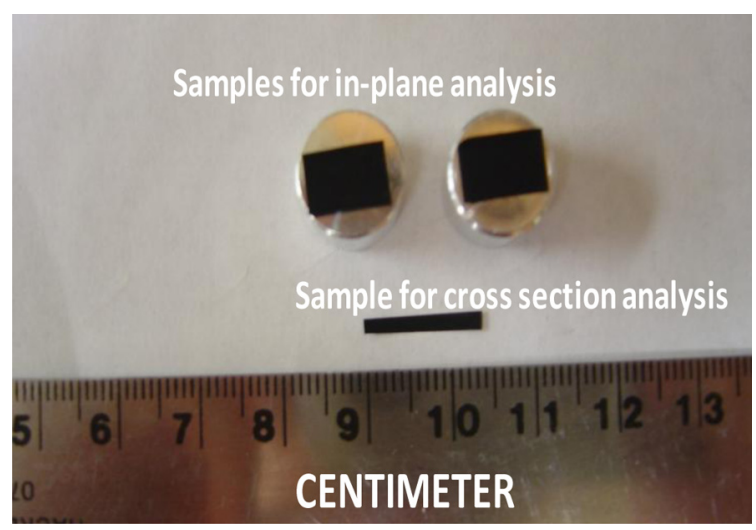

Fig. 1. Aluminum stubs and samples used for SEM characterization.

humidity. Some other articles regarding testing and modeling of the mechanical behavior of fuel cell membranes are also available in the literature [11,12,16-25].

However, little work has been published regarding the mechanical behavior of the electrodes. This is due to the fact that the electrodes are typically painted or sprayed onto the membrane during manufacturing and therefore do not exist as independent solid materials. Consequently, it is difficult to directly characterize the mechanical behavior of the electrodes. In this work, we devised an experimental-numerical hybrid technique to determine the mechanical behavior of the electrodes. Tensile and relaxation tests have been conducted to characterize the time-dependent mechanical behavior of both Nafion ${ }^{\circledR} 211$ membranes and GORE ${ }^{\text {TM }}$ PRIMEA $^{\circledR}$ MEAs ${ }^{2}$ based on Nafion ${ }^{\circledR} 211$ membranes at various temperatures, humidities, and strain rates. Within the linear regime, the rule-ofmixtures assuming an iso-strain condition can be used to calculate the rate-dependent Young's modulus of the electrodes. Beyond the linear regime, however, the problem becomes highly non-linear with the onset of plasticity, strain hardening, and mechanical damage. Therefore, we used finite element models, created in the commercial software ABAQUS 6.9 [26], to conduct reverse analyses for determining the electrode mechanical behavior at moderate to large strain.

Furthermore, mechanical damage mechanisms such as cracks and delaminations play a role in the mechanical behavior of the MEA. However, once a material has completely failed, it is generally difficult to identify the failure evolution. By performing interrupted tests at selected strain levels under uniaxial tension, we were able to characterize how the mechanical damage develops as the strain increases. This information was then incorporated into the finite element models to simulate the stress-strain response of the MEA up to strains of 0.4.

In the following, we will briefly review the experimental procedure to determine the mechanical behavior of the membranes and MEAs, followed by the numerical work and reverse analysis used to determine the electrode properties.

\section{Experimental procedure}

Details pertaining to the experimental procedure for determining the mechanical properties of Nafion ${ }^{\circledR} 211$ membranes are discussed in our previous work [15]. A similar experimental procedure was employed to characterize the MEAs, and will be briefly reviewed here for clarity. The interrupted tension tests will also be discussed. The MEAs used in this study were manufactured at W.L. Gore \& Associates Inc., using Nafion ${ }^{\circledR} 211$ membrane material, nominally $24 \mu$ thick, affixed with GORE ${ }^{\mathrm{TM}}$ PRIMEA ${ }^{\circledR}$ electrodes, by way of their proprietary

\footnotetext{
${ }^{2}$ GORE PRIMEA is a registered trademark of W.L. Gore \& Associates, Inc.
}

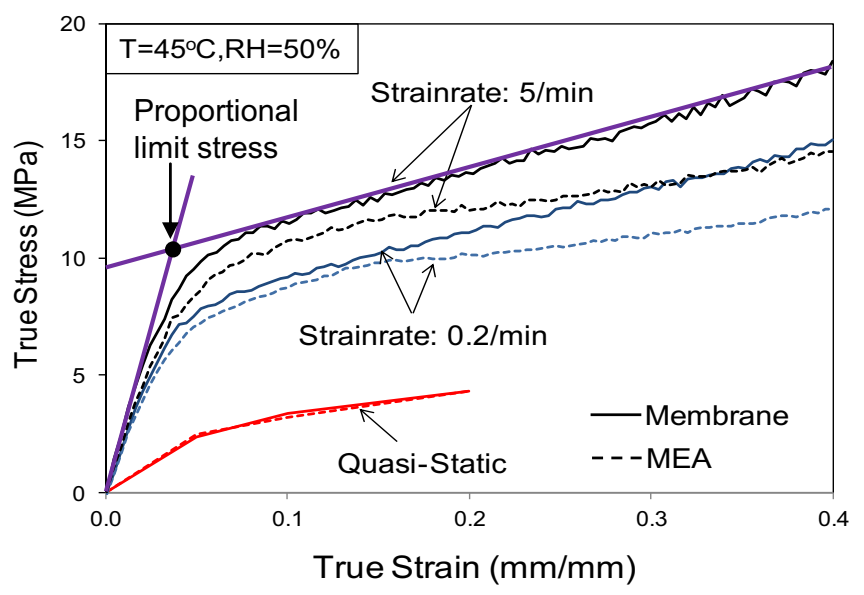

Fig. 2. True stress as a function of true strain for Nafion ${ }^{\circledR} 211$ membrane [15] and the MEA at selected strain rates with $T=45^{\circ} \mathrm{C}, \mathrm{RH}=50 \%$ (the quasi-static results are derived from relaxation tests).

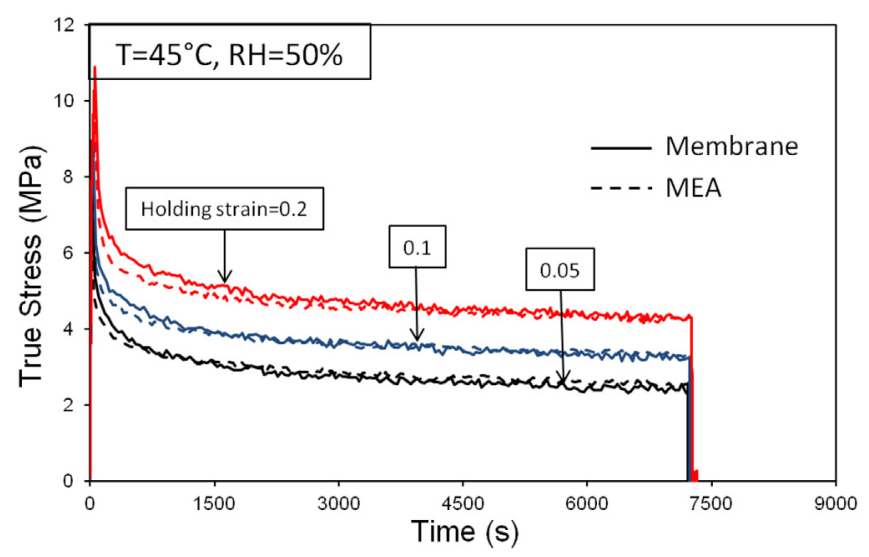

Fig. 3. True stress as a function of time for relaxation tests of Nafion ${ }^{\circledR} 211$ membrane and MEA at selected holding strains for $T=45^{\circ} \mathrm{C}, \mathrm{RH}=50 \%$.

electrode deposition process. The cathode was nominally $12 \mu$ thick and made from GORE ${ }^{\mathrm{TM}}$ PRIMEA $^{\circledR} 580.3$, with platinum loading of $0.3 \mathrm{mg} \mathrm{cm}{ }^{2}$ and the anode is nominally $6 \mu$ thick and made from GORE $^{\text {TM }}$ PRIMEA ${ }^{\circledR} 584.1$, with platinum loading of $0.1 \mathrm{mg} \mathrm{cm}^{2}$.

\subsection{Tensile and relaxation tests}

We measured the time-dependent mechanical properties of Nafion ${ }^{\circledR} 211$ membranes and MEAs based on Nafion ${ }^{\circledR} 211$ membranes at three strain rates $\left(5.0,0.2,0 \mathrm{~mm} \mathrm{~mm}^{-1}\right.$ per minute ${ }^{3}$ ) (in the following, the notation/min will be used for simplicity) for sixteen temperature and relative humidity combinations, i.e. four selected temperatures $\left(25,45,65,80^{\circ} \mathrm{C}\right)$ and four selected relative humidities (30, 50, 70, 90\%).

The tests were conducted using an MTS Alliance ${ }^{\mathrm{TM}} \mathrm{RT} / 5$ material testing system fitted with an ESPEC custom-designed environmental chamber [15]. The environmental chamber was used to set the desired temperature and relative humidity for testing. We conducted two sets of experiments at each environmental condition: tensile tests and relaxation tests. The tensile tests were conducted at two selected strain rates $\left(5 \mathrm{~min}^{-1}\right.$ and $\left.0.2 \mathrm{~min}^{-1}\right)$ and the relaxation tests, at three selected holding strains $(0.05,0.1$ and 0.2$)$ [15].

\footnotetext{
${ }^{3}$ We also conducted a limited set of tensile tests at higher strain rates (up to $12 \mathrm{~min}^{-1}$ ) and found very similar stress-strain response to the response seen at the strain rate of $5 \mathrm{~min}^{-1}$.
} 
Table 1

Young's modulus and proportional limit stress of Nafion ${ }^{\circledR} 211$ membrane and the MEA based on Nafion ${ }^{\circledR} 211$ membrane as a function of temperature, humidity, and strain rate.

\begin{tabular}{|c|c|c|c|c|c|}
\hline $\begin{array}{l}\text { Temperature/ } \\
\text { humidity }\end{array}$ & $\begin{array}{l}\text { Strain rate } \\
\left(\mathrm{mm} \mathrm{mm}^{-1}\right. \\
\text { per minute) }\end{array}$ & $\begin{array}{l}\text { Modulus } \\
\text { membrane } \\
\text { (MPa) }\end{array}$ & $\begin{array}{l}\text { Modulus } \\
\text { MEA } \\
(\mathrm{MPa})\end{array}$ & $\begin{array}{l}\text { Proportional } \\
\text { limit stress } \\
\text { membrane } \\
(\mathrm{MPa})\end{array}$ & $\begin{array}{l}\text { Proportional } \\
\text { limit stress } \\
\text { MEA (MPa) }\end{array}$ \\
\hline $45^{\circ} \mathrm{C} / 50 \%$ & 0.0 & 45.9 & 46.5 & 2.3 & 2.3 \\
\hline $45^{\circ} \mathrm{C} / 50 \%$ & 0.2 & 210.2 & 188.8 & 7.9 & 6.9 \\
\hline $45^{\circ} \mathrm{C} / 50 \%$ & 5.0 & 248.1 & 224.7 & 10.6 & 7.8 \\
\hline $45{ }^{\circ} \mathrm{C} / 90 \%$ & 0.2 & 165.4 & 135.1 & 6.3 & 4.1 \\
\hline $80{ }^{\circ} \mathrm{C} / 90 \%$ & 0.2 & 66.1 & 60.7 & 3.9 & 2.9 \\
\hline
\end{tabular}

We tested three specimens at each combination of temperature, humidity and tensile loading rate or relaxation holding strain. For each specimen, the pretest thickness and width were measured with a micrometer and a caliper, respectively, at three locations along the sample before testing. The averages of these three measurements were used as the nominal dimensions of the sample under ambient conditions. The $20 \mathrm{~mm}$ wide specimen was aligned with the extension rod and clamped into a pair of vise-action grips to provide a nominal gauge length of $50 \mathrm{~mm}$ as determined by the grip separation [15].

To achieve the desired environmental conditions in the chamber, the temperature was first set to the desired value and allowed to stabilize, and then the humidity was slowly increased (or decreased) to the desired relative humidity $(\mathrm{RH})$ with the specimen slack. Both the temperature and humidity were kept at the desired values for at least half hour before applying tension to ensure that the specimen equilibrated with the surroundings. During this process, the length of the specimen changes due to the thermal and swelling deformations. Before applying a force, the crosshead was manually adjusted until the initial force applied to the specimen was brought to a small, finite tensile force $(\sim 0.01 \mathrm{~N})$, eliminating the initial slack
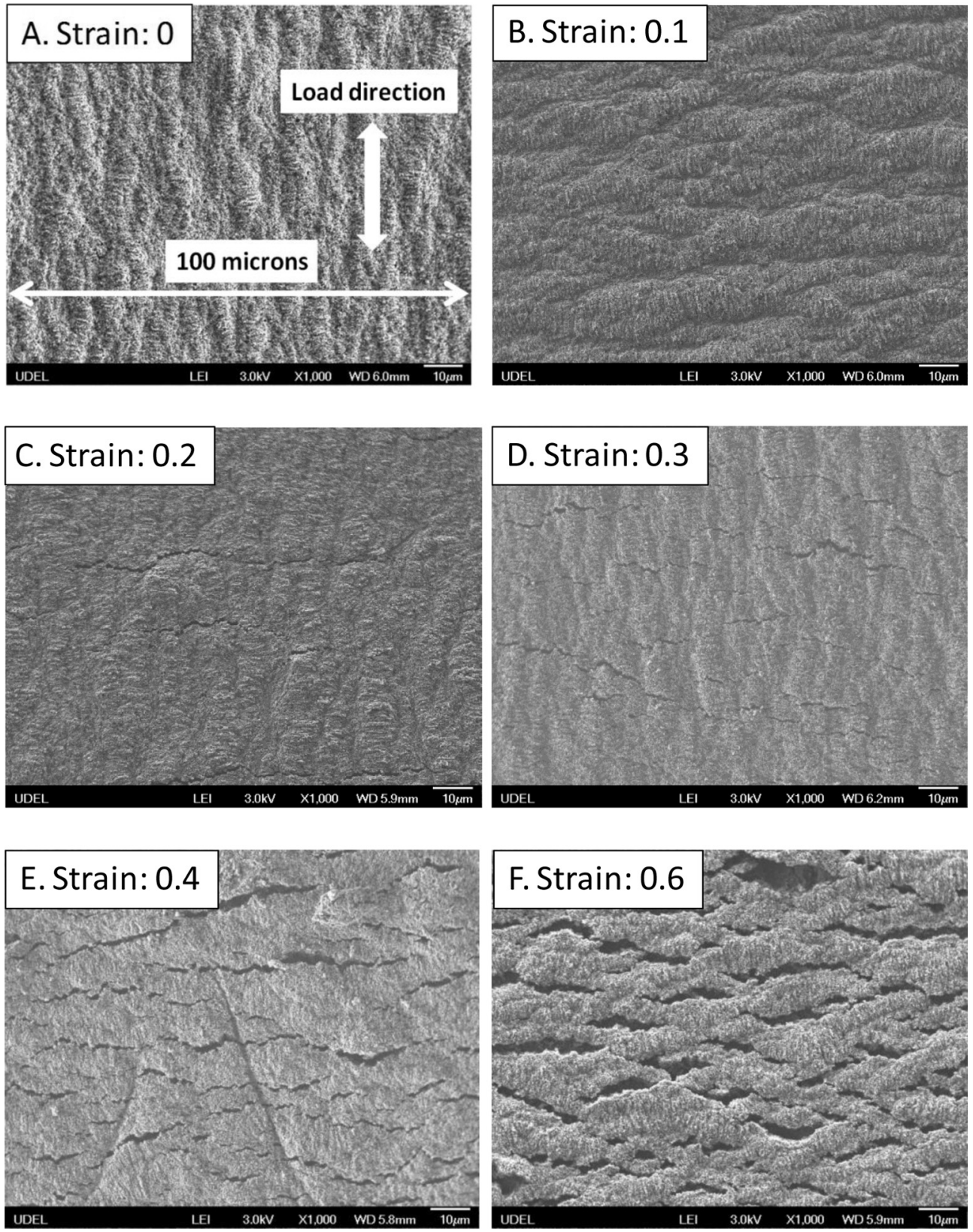

Fig. 4. SEM images of the MEA in-plane surface loaded to selected strain levels of $0,0.1,0.2,0.3,0.4$ and 0.6 at the strain rate of 0.2 min ${ }^{-1}$ with $T=25{ }^{\circ} \mathrm{C}$, $\mathrm{RH}=30 \%$. 
caused by thermal and swelling expansions. For calculating the subsequent strain, we took the reference length of the specimen to be the original length at ambient conditions, plus the total displacement of the crosshead corresponding to the change in length caused by the change in environmental conditions.

\subsection{Interrupted tension tests}

The interrupted tension tests were conducted at four selected temperature-humidity conditions $\left(T=25{ }^{\circ} \mathrm{C} / \mathrm{RH}=30 \%\right.$, $\left.T=25^{\circ} \mathrm{C} / \mathrm{RH}=90 \%, T=80^{\circ} \mathrm{C} / \mathrm{RH}=30 \%, T=80^{\circ} \mathrm{C} / \mathrm{RH}=90 \%\right)$ and two strain rates $\left(0.2 \mathrm{~min}^{-1}, 5.0 \mathrm{~min}^{-1}\right)$ using the same experimental setup as in Section 2.1. Since the objective was to obtain the detailed micro-structural damage evolution of the MEA, the interrupted tests were performed up to selected true-strain levels of $0.1,0.2,0.3$ and 0.4 as calculated from the load-displacement data.

After the specimens were subjected to the interrupted tests, two types of samples were cut from each: (1) a rectangular piece of approximately $10 \mathrm{~mm}$ in length and $5 \mathrm{~mm}$ in width to evaluate the extent of in-plane surface cracking; and (2) a slender piece of approximately $10 \mathrm{~mm}$ in length to evaluate the cracks in a crosssectional view (Fig. 1). Observations were made using a scanning electron microscope (JSM-7400F) with a wide range of magnifications from $25 \times$ to $300,000 \times$. By scanning the specimen surface, it was possible to collect data about the damage including individual crack location, orientation and crack length as well as crack density. Looking at the cross section of the sample gave information about the depth of the cracks and the existence and extent of delamination.
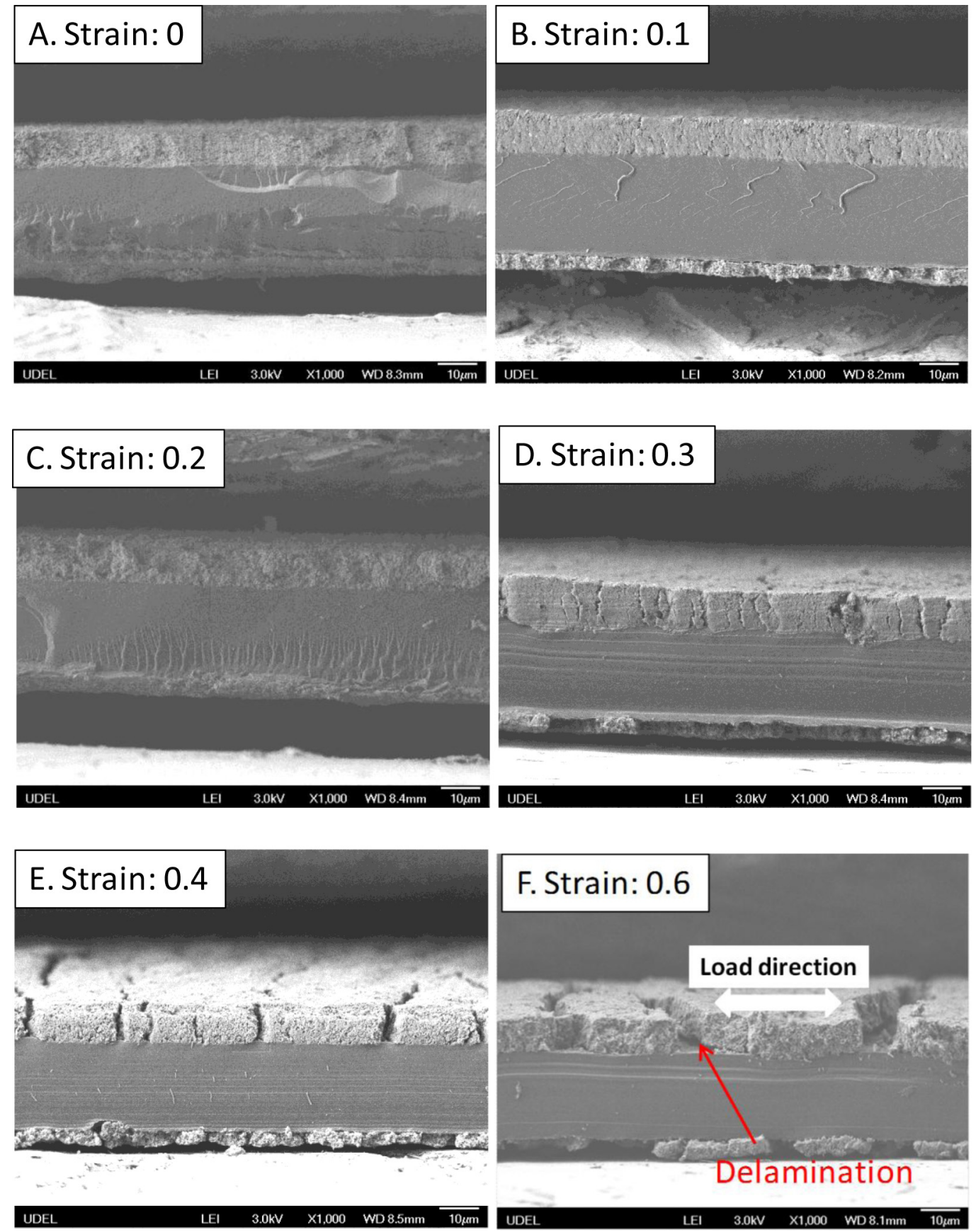

Fig. 5. SEM images of the MEA cross-sectional surface loaded to selected strain levels of $0,0.1,0.2,0.3,0.4$ and 0.6 at the strain rate of $0.2 \min ^{-1}$ with $T=25{ }^{\circ} \mathrm{C}$, $\mathrm{RH}=30 \%$. 


\section{Experimental results}

\subsection{Tensile and relaxation tests}

Fig. 2 shows typical true stress-true strain curves for Nafion ${ }^{\circledR} 211$ membrane and the MEA at $45{ }^{\circ} \mathrm{C}$ and $50 \%$ relative humidity for several strain rates. True stress, $\sigma_{\text {true, }}$ and true strain, $\varepsilon_{\text {true, }}$ relationships are used to take into account large deformation and can be related to engineering stress, $\sigma_{\mathrm{eng}}$, and engineering strain, $\varepsilon_{\mathrm{eng}}$, through the equations,

$\sigma_{\text {true }}=\left(1+\varepsilon_{\text {eng }}\right) \sigma_{\text {eng }}$

$\varepsilon_{\text {true }}=\ln \left(1+\varepsilon_{\text {eng }}\right)$.

Fig. 3 shows typical stress-time curves for relaxation tests. The sample is held at constant strains of $0.05,0.1$, and 0.2 respectively. The stress decreases quickly during the first few minutes, and the rate of decrease gradually slows until it is changing very slowly after $2 \mathrm{~h}$. In an actual relaxation test, the sample would be held at this constant strain until the stress reaches an equilibrium value. However, due to limitations in the testing equipment and practical considerations in the current study, we ran the relaxation tests for $2 \mathrm{~h}$ and assumed that the stress level at that time was the equilibrium stress. By assuming that the zero strain condition corresponds to a stress free state, we fitted a curve through zero and the three equilibrium stresses determined from the relaxation tests to get an approximation to the quasi-static stress-strain curve for tensile tests as shown in Fig. 2.
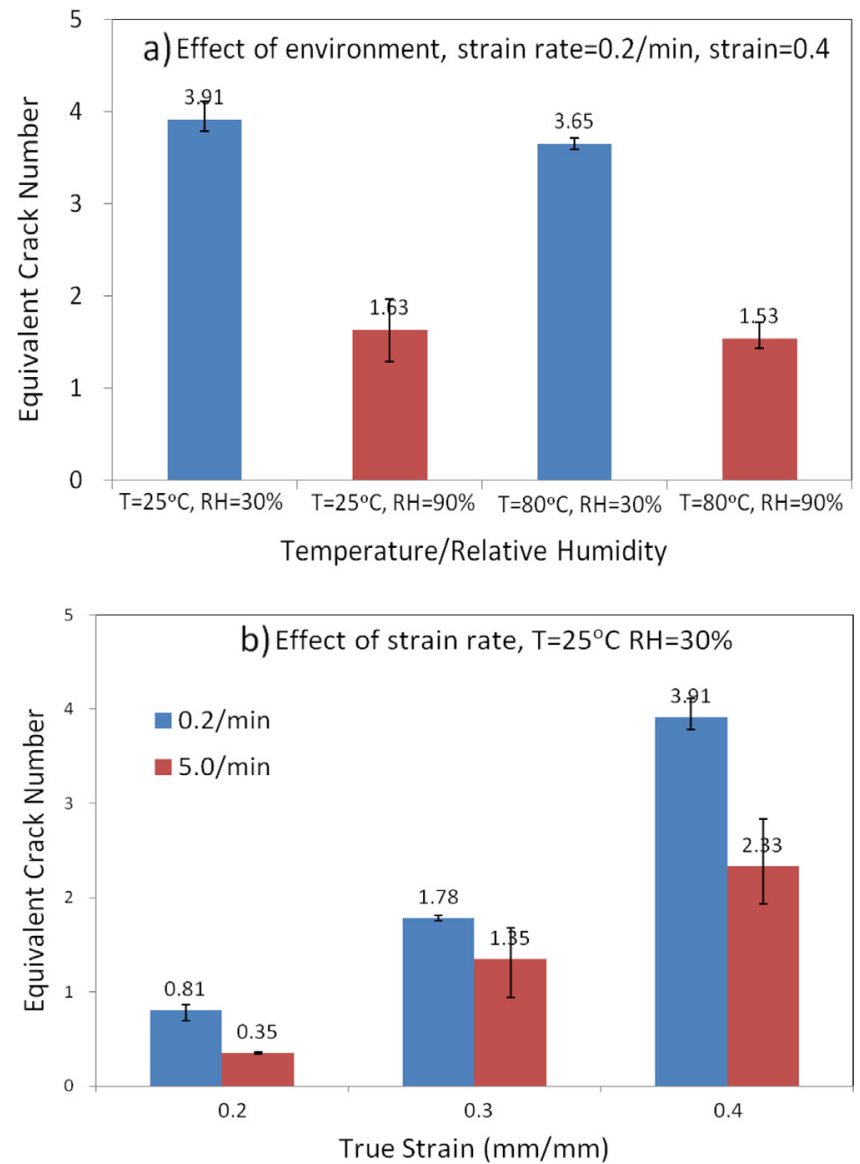

Fig. 6. Effects of a) environment (temperature/humidity), and b) strain rate on the equivalent crack number.
Both the membrane and MEA are stiffer at higher strain rates, and the MEA produces a smaller stress than the membrane at a given strain and strain rate (Fig. 2). Under quasi-static conditions, however, the true stress-true strain curves of the membrane and the MEA nearly coincide. This indicates that the electrode has a similar true stress-true strain response to the membrane under quasi-static loading since the MEA is a layered structure consisting of the membrane and electrodes.

Based on the true stress-true strain response, mechanical properties such as Young's modulus and proportional limit stress were determined. The initial slope of the tensile true stress-true strain response is taken as the rate-dependent Young's modulus for the material. However, based on the monotonically increasing load used in the tests (Fig. 2), it is not possible to identify the onset of yielding or a yield limit. Instead, we report the proportional limit stress, which we have defined graphically as the stress at the intersection of the tangents to the initial linear portion of the curve and the initial strain hardening response (Fig. 2) [12].

The average Young's modulus and proportional limit stress of the two types of samples at selected strain rate/temperature/humidity combinations are summarized in Table 1 . The results suggest that similar to Nafion ${ }^{\circledR} 211$ membrane, Young's modulus and proportional limit stress of the MEA increase as the strain rate increases, temperature decreases or humidity decreases. Furthermore, the MEA has a lower Young's modulus and proportional limit stress than Nafion ${ }^{\circledR} 211$ membrane at strain rates of $0.2 \mathrm{~min}^{-1}$ and $5.0 \mathrm{~min}^{-1}$. For the quasi-static condition, the two types of samples have nearly the same properties.
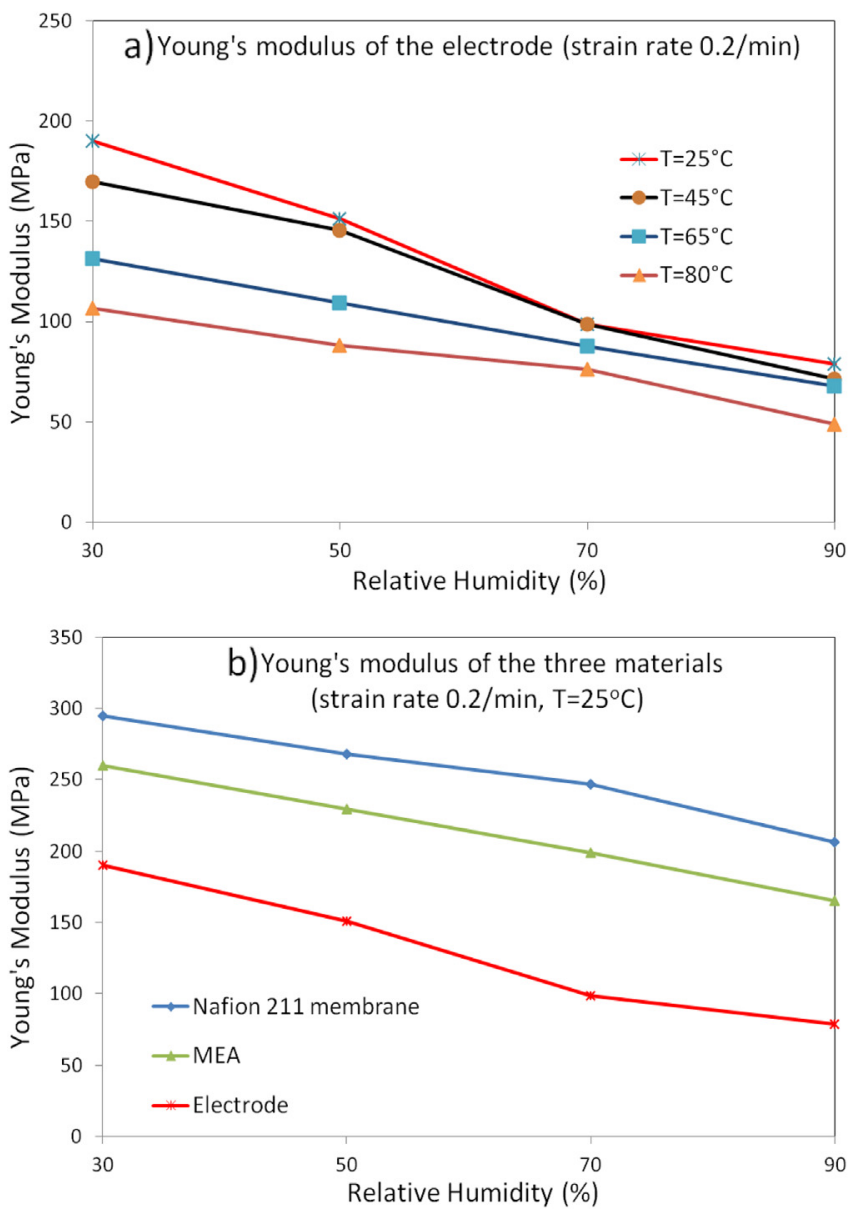

Fig. 7. Young's modulus of a) the electrode at a strain rate of $0.2 \mathrm{~min}^{-1}$, and b) the electrode, membrane and MEA at a strain rate of $0.2 \mathrm{~min}^{-1}$ and $T=25^{\circ} \mathrm{C}$. 


\subsection{Interrupted tension tests}

Fig. 4 shows SEM images of the MEA plane surface after interrupted tension tests, up to strain levels from 0 to 0.6 . The specimens were loaded at a strain rate of $0.2 \mathrm{~min}^{-1}$ with $T=25^{\circ} \mathrm{C} / \mathrm{RH}=30 \%$. The images suggest that cracking initiates between strain levels of 0.1 and 0.2 , and that the crack density increases as the strain increases. The images also show that cracking develops perpendicular to the direction of tensile loading. Fracture information such as crack length (in the plane) and crack density has been quantified for all conditions considered to provide input for the finite element models used to determine the electrode's mechanical behavior (discussed below).

We also investigated the interfacial delamination between the membrane and electrodes. Fig. 5 shows SEM images of the MEA crosssectional surface after interrupted tension tests, up to strain levels from 0 to 0.6 . The specimens were loaded at a strain rate of $0.2 \mathrm{~min}^{-1}$ with $T=25{ }^{\circ} \mathrm{C} / \mathrm{RH}=30 \%$. The figure shows that the delamination initiates around the tip of the vertical cracks through the electrode, and that the vertical cracks are limited to the electrode layers.

The professional statistical software package, Image,${ }^{4}$, was used to analyze and summarize all the crack information. For each condition, a non-dimensional crack density parameter, $\Gamma$, was calculated to characterize the crack distribution with a single parameter. In an image of area $A$ with $N$ cracks of individual length $\iota_{i}$, the crack density parameter $\Gamma$ can be determined from the following relationship [27]:

$\Gamma=\frac{\sum_{i=1}^{N} \iota_{i}^{2}}{A}$

Two distributions of micro-cracks can be assumed to have a similar effect on the overall constitutive response of the system when they have the same crack density parameter [27]. Thus, to simulate the mechanical response with a set of simple 2D models, the $N$ cracks with various lengths in a representative area can be modeled as $M$ cracks with a same crack length $L$, where $M$ is the equivalent crack number. In this study, $L$ was assumed to be the width of the SEM images $(100 \mu)$ as shown in Fig. 4 . The equivalent crack number $M$ can be calculated according to the following equation:

$\Gamma=\frac{\sum_{i=1}^{N} \iota_{i}^{2}}{A}=\frac{M L^{2}}{A}$

The results suggest that at higher humidity and at higher strain rate fewer cracks develop, and that temperature has little effect on the crack number (Fig. 6). We believe that this is the result of a competition between the crack driving force and fracture toughness.

In addition, we also conducted parametric numerical simulations to verify that the cracks generated in the interrupted tests remain open during imaging. This is discussed in the Appendix.

\section{Determination of the electrode behavior}

\subsection{Linear properties}

Within the linear regime, the rule-of-mixtures was used to determine Young's modulus of the electrode since the MEA is a simple layered structure of the membrane and electrodes.

For uniaxial tension, it can be assumed that the overall strains, $\varepsilon$, in the individual layers and the MEA in the loading direction are the same (iso-strain):

$\varepsilon_{\mathrm{MEA}}=\varepsilon_{m}=\varepsilon_{e}$

\footnotetext{
${ }^{4}$ ImageJ can be downloaded for free at http://rsbweb.nih.gov/ij/download.html.
}

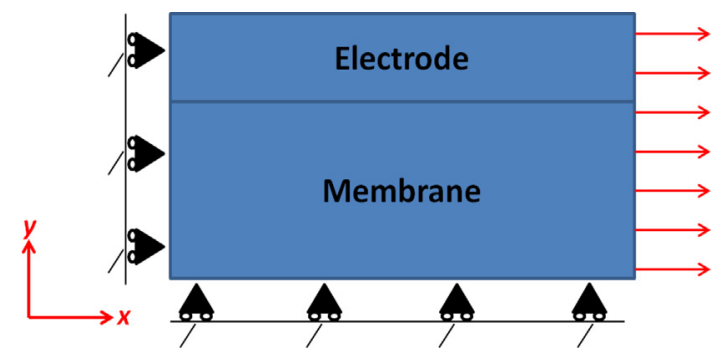

Fig. 8. Representation of the two-dimensional numerical model used to determine the mechanical properties of the electrodes; the bottom edge is prevented from moving in the $y$ direction and the left edge is prevented from moving in the $x$ direction; uniform load is applied on the right edge.

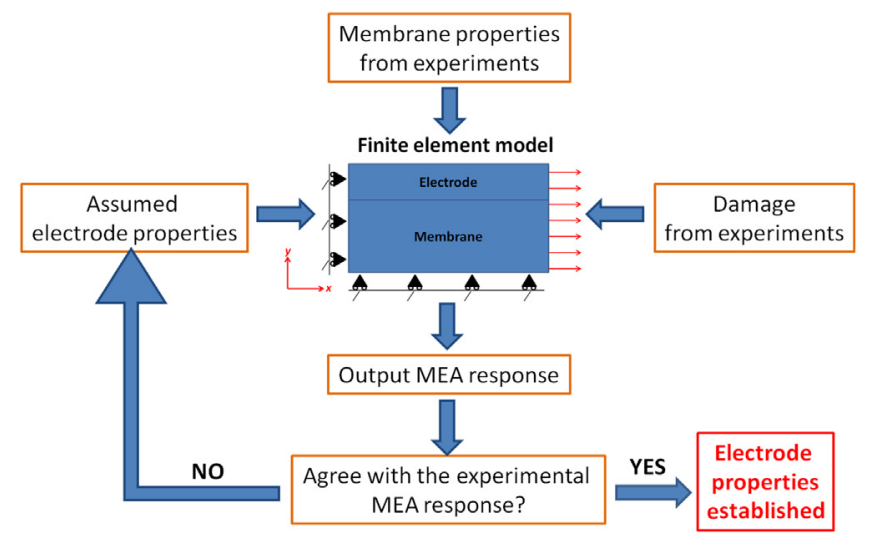

Fig. 9. The reverse analysis used to determine the electrode properties beyond the linear regime.

where the subscripts MEA, $m$ and $e$ represent the membrane electrode assembly, membrane and electrode, respectively. The resultant force on the MEA consists of the force on the membrane and the force on the electrodes:

$F_{\mathrm{MEA}}=F_{m}+F_{e}$

Furthermore, assuming a uniform uniaxial (1-D) stress distribution and considering Hooke's Law,

$\sigma=E \varepsilon$

$F=\sigma A$

We obtain

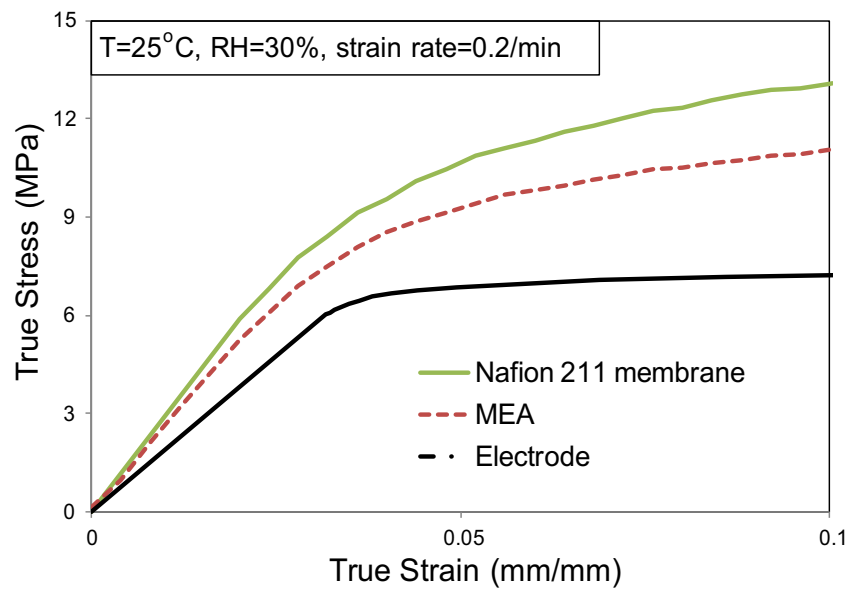

Fig. 10. True stress as a function of true strain for the membrane, MEA and electrode at $0.2 \mathrm{~min}^{-1}$ and $T=25^{\circ} \mathrm{C}, \mathrm{RH}=30 \%$, up to strain of 0.1 . 

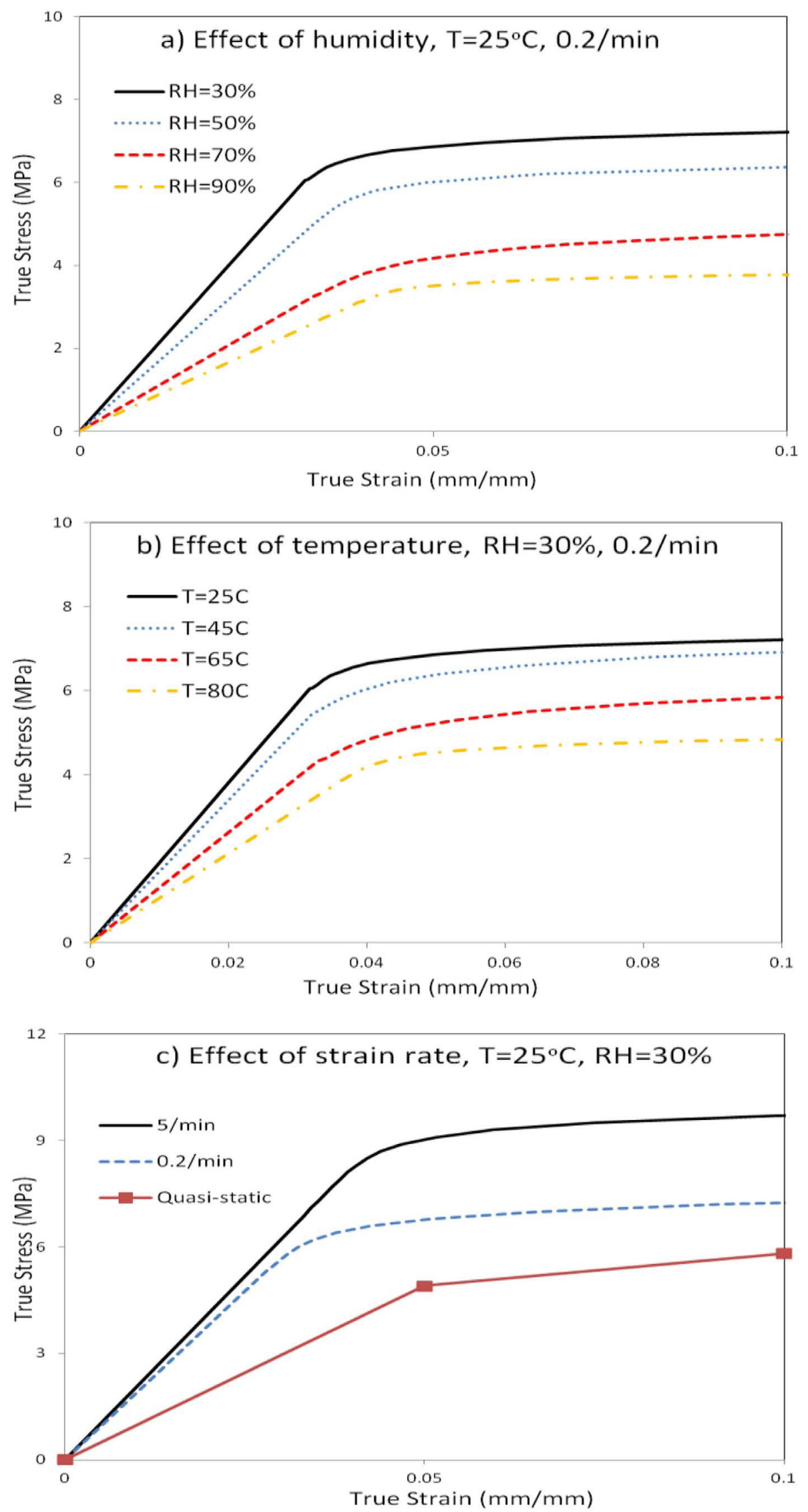

Fig. 11. The effect of a) humidity, b) temperature, and c) strain rate on the calculated true stress-true strain response of the electrode, up to strain of 0.10 . 
$(E \varepsilon A)_{\mathrm{MEA}}=(E \varepsilon A)_{m}+(E \varepsilon A)_{e}$

where $\sigma, E, \varepsilon$ and $A$ represent the stress, elastic modulus, strain and cross-sectional area, respectively. By using Eq. (4) to cancel the strains, this equation can be used to calculate Young's modulus for the electrode, given the elastic properties of the membrane and MEA and the thickness of the individual layers in the MEA, which were obtained from the tensile and relaxation tests described in Section 2.1. The results of these calculations are shown in Fig. 7.

Fig. 7a shows that Young's modulus of the electrode decreases as the temperature or humidity increases, similar to the behavior of Young's modulus for Nafion ${ }^{\circledR} 211$ membrane. Fig. 7b shows that the electrode has a lower Young's modulus than the Nafion ${ }^{\circledR} 211$ membrane and the MEA modulus is intermediate between the two (this is expected since the MEA is a layered structure composed of the membrane and electrodes).

\subsection{Non-linear properties}

Beyond the linear regime, plasticity, strain hardening, and mechanical failure mechanisms cause non-linearities, which preclude the use of the rule-of-mixtures. Consequently, a two-dimensional finite element model (Fig. 8) was developed using the commercial software ABAQUS 6.9 to determine the non-linear electrode properties via reverse analysis. Since symmetry conditions were assumed, a representative segment of the MEA was modeled using a quarter of the structure. The boundary conditions: $u_{\mathrm{y}}=0$ on the bottom edge and $u_{\mathrm{x}}=0$ on the left edge were imposed. Generalized plane strain was assumed and a uniform $x$-displacement condition was applied on the right edge.

The mechanical properties of the Nafion ${ }^{\circledR} 211$ membrane and electrodes are required input for the finite element model. While the properties of the Nafion ${ }^{\circledR} 211$ membrane are known from the experiments described above, the properties of the electrodes are the objective of the analysis and are unknown. Therefore, representative values are assumed and varied in the model for a series of successive runs. When the true stress-true strain response of the MEA from the model agrees with the experimental results for the MEA, it can be assumed that the constitutive properties of the electrodes used in the model correspond to the actual properties of the electrodes. The flow chart in Fig. 9 illustrates the general methodology.

The SEM images from the interrupted tension tests showed that electrode cracks initiate between strains of 0.1 and 0.2 . Therefore, fracture is not involved for strains up to 0.1 , and we implemented a commonly-used empirical stress-strain relationship [28] to capture the linear plus the initial non-linear behavior of the electrode before cracking:

$\varepsilon=\frac{\sigma}{E}+K\left(\frac{\sigma}{E}\right)^{n}$

In this relationship, the rate-dependent Young's modulus of the electrodes, $E$ was previously determined from the rule-of-mixtures analysis described in Section 4.1. The terms $K$ and $n$ are material parameters, which depend on temperature and humidity that characterize the non-linear portion of the curve, and are typically obtained by fitting the equation to the experimental data for each temperature and humidity condition. In this work, $K$ and $n$ (in the constitutive relationship for the electrodes) were systematically varied in the finite element model of the MEA (Fig. 8). When the true stress-true strain response of the MEA from the finite element model agreed with the experimental results, we assumed that the electrode properties used in the model corresponded to the actual properties of the electrodes.

Fig. 10 shows a typical comparison of the true stress-true strain response of the membrane, MEA and electrode, up to a strain of 0.1 .

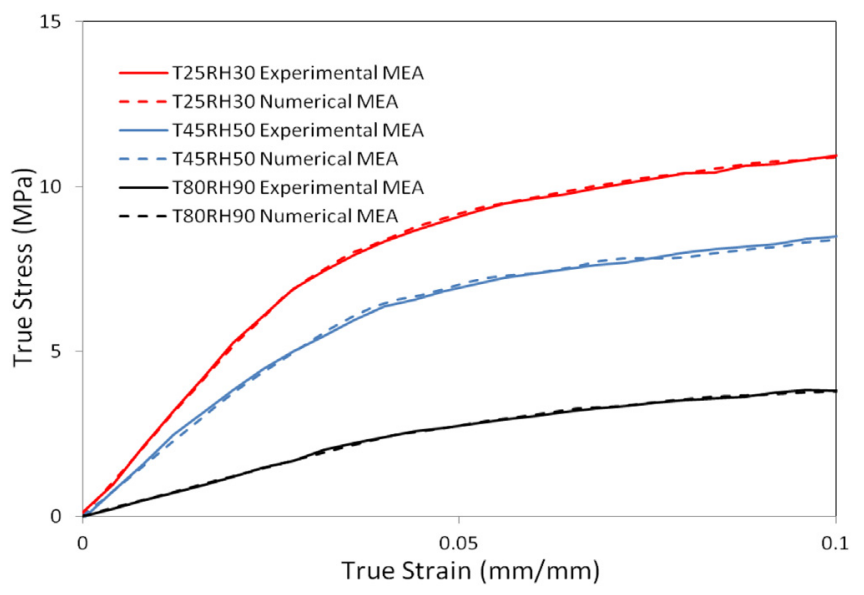

Fig. 12. Predicted true stress as a function of true strain for the MEA, compared to the experimental MEA response, at $T=25^{\circ} \mathrm{C} / \mathrm{RH}=30 \%, T=45^{\circ} \mathrm{C} / \mathrm{RH}=50 \%$ and $T=80^{\circ} \mathrm{C} /$ $\mathrm{RH}=90 \%$ with a strain rate of $0.2 \mathrm{~min}^{-1}$.

Fig. 11 shows the derived true stress-true strain response of the electrode up to a strain of 0.1 for various combinations of temperature, humidity and strain rate. Similar to the behavior of the membrane, the electrode becomes stiffer as the temperature decreases, humidity decreases, or strain rate increases. Note that the $K$ and $n$ values thus derived, give reasonable predictions for the stress-strain behavior of the MEA up to strains of 0.1 (Fig. 12).

When the strain is higher than 0.1, however, the response from the empirical equation (Eq. (9)) deviates significantly from the response observed in the experiments. The results from the interrupted tension experiments indicate that this deviation may be due to the onset of cracking. Therefore, the damage evolution information obtained from the interrupted tests was incorporated to the numerical model to simulate the electrode response beyond strain 0.1 . The details are not presented here for conciseness. Note that in real operations of PEM fuel cells, the strains in the membrane and electrodes normally do not go beyond 0.1 .

The derived time-dependent mechanical behavior of the electrode, as a function of strain rate, temperature and humidity, can be defined and used in finite element models through a two-layer viscoplastic constitutive model [25].

\section{Concluding remarks}

Since it is difficult to directly measure electrode mechanical properties, we have devised an experimental-numerical hybrid technique to determine the time-dependent mechanical behavior of the fuel cell electrodes. Tensile and relaxation tests have been conducted to characterize the time-dependent mechanical behavior of both Nafion ${ }^{\circledR} 211$ membranes and MEAs based on Nafion ${ }^{\circledR} 211$ membranes at various temperatures, humidities, and strain rates. We found that the MEAs have lower Young's modulus and proportional limit stress than Nafion ${ }^{\circledR} 211$ membranes. We also found that Young's modulus and proportional limit stress of the MEAs are affected by the temperature, humidity and strain rate in a similar way to the effects on Nafion ${ }^{\circledR} 211$ membranes. The rule-of-mixtures together with an iso-strain condition were then used to determine the rate-dependent Young's modulus of the electrodes. The results indicate that the electrodes generally have lower Young's modulus than Nafion ${ }^{\circledR} 211$ membranes. Under quasi-static conditions, however, the membrane, electrode and MEA have very similar Young's modulus.

Beyond the initial linear regime, the behavior becomes non-linear and requires a more sophisticated modeling approach. Therefore, reverse analysis based on finite element models was conducted to 
determine the electrode behavior at moderate to large strains. In addition, interrupted tension tests at various strain levels were conducted in order to collect crack evolution information for the MEA. We found that cracks in the electrodes initiate between strains of 0.1 and 0.2 perpendicular to the direction of tensile loading. Finite element simulations showed that it is unlikely that cracks initiated at a lower strain level, and closed before SEM examination (see Appendix).

Quantification of the crack information shows that in the range of values tested, higher humidity or larger strain rate leads to fewer cracks, and that temperature has little effect on the crack number. These fracture observations were then incorporated to the finite element models for determining the electrode behavior at large strain levels. The results show that the electrodes have similar behavior to Nafion ${ }^{\circledR} 211$ membrane as a function of strain rate, temperature and humidity, but have lower Young's modulus and proportional limit.

\section{Acknowledgments}

This research has been supported by W.L. Gore \& Associates under a grant (DE-FC36-086018052) from the United States Department of Energy.

\section{Appendix. On crack closure during unloading}

In our interrupted tension tests, the MEA sample was first loaded to the established strain level in the MTS material testing system, then unloaded and moved to the SEM for characterization. During this process, cracks that developed during the tensile loading might close during the unloading and therefore become invisible, or nearly so, when observed in SEM, as illustrated in Fig. A1. In this case, the number of the cracks observed from the SEM would be smaller than the actual number of cracks developed and cracking might initiate at a lower strain level. In-situ testing, i.e. conducting tensile tests inside the SEM chamber, could be used to overcome this problem. Alternatively, we conducted a numerical experiment to test for this crackclosing phenomenon in our interrupted tests.

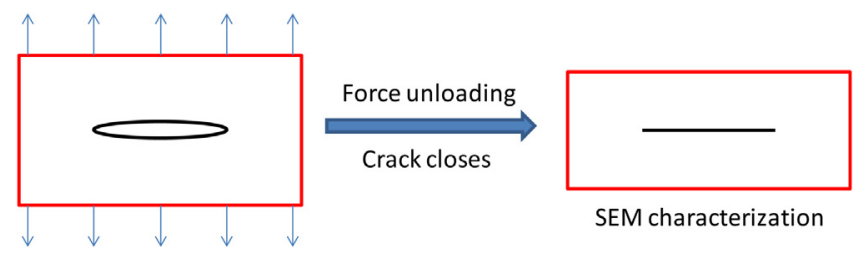

Figure A1. Schematic of crack closing during unloading.

A two-dimensional finite element model (Fig. A2) was developed using the commercial software ABAQUS 6.9. A representative segment of the MEA was modeled as described above.

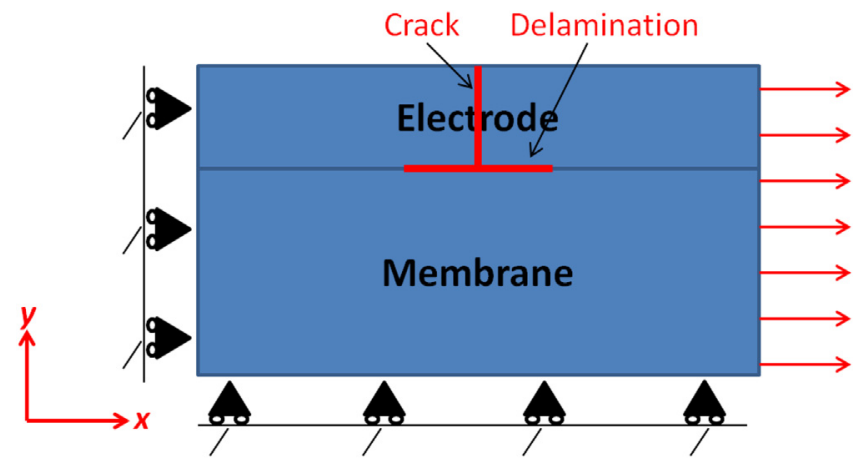

Figure A2. Representation of the two-dimensional numerical model used to investigate the failure mechanisms in the MEA.
In this model, a single electrode crack was allowed to develop and propagate through the thickness of the electrode during the simulated tensile loading and then the structure was unloaded. The measured elastic-plastic properties of the membrane and derived properties of the electrode were incorporated in the model. The simulations were conducted via a force controlled loading to obtain a pre-determined overall strain. If the crack closed during unloading in the simulation, we assume it would be likely that the crack would close in a real experiment as well. If not, it would likely be seen in the SEM image.

Fig. A3 shows images of the simulated MEA when it was loaded to a maximum strain of 0.1 and then unloaded. During the tensile loading, an electrode through-crack was assumed to initiate at an early strain (e.g. 0.02). The simulation shows that under these conditions, the crack stays open after unloading. This is due to that the crack tip introduces a stress concentration, causing local yielding. The permanent plastic deformation prevents the crack from closing completely. The force and strain evolution are plotted as functions of time in Fig. A4, showing that the overall strain does not go back to zero when the applied load is released.

A parametric numerical studying of this process varying the maximum loading strain, crack initiation strain and crack length

\section{a) At the end of loading}

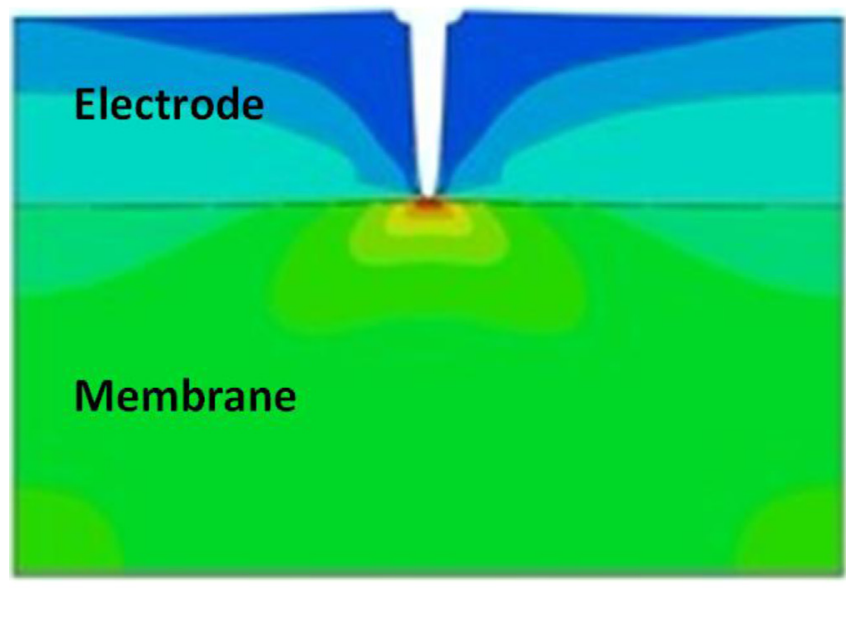

\section{b) At the end of unloading}

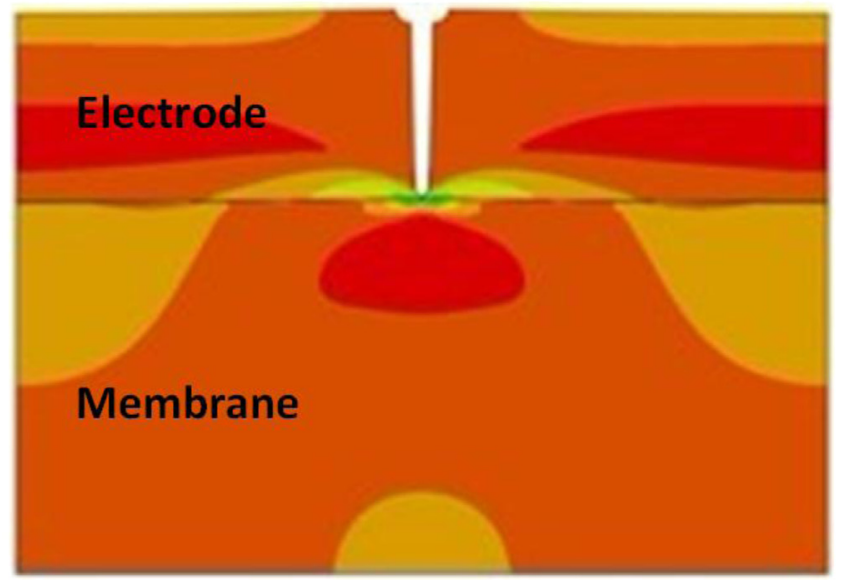

Figure A3. Images of the MEA at the end of a) loading, and b) unloading. The crack stays open after unloading. 


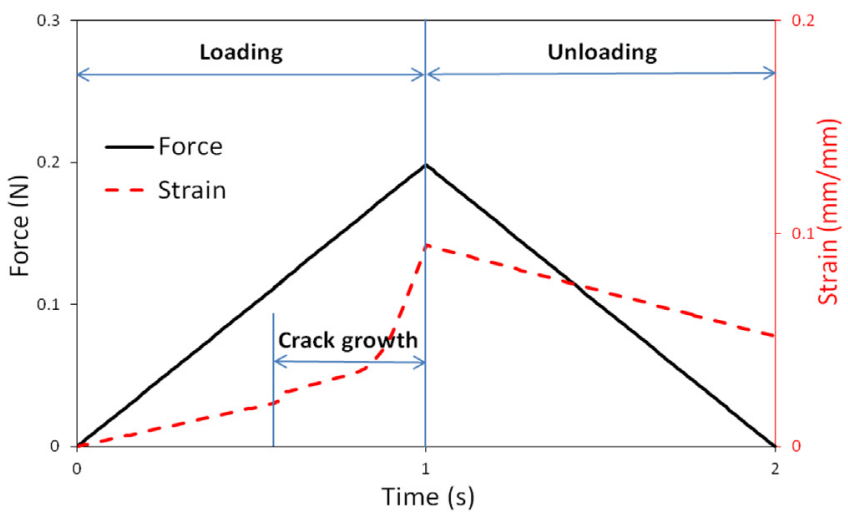

Figure A4. Force and strain evolution during the loading-unloading cycle.

was conducted (not presented here for conciseness). The results suggest that cracks developed at strains levels less than 0.1 during tensile loading would most likely stay open after unloading due to the plasticity in the membrane, and therefore would be observed by SEM. However, since no cracks were observed at a strain of 0.1 in the experiments, we conclude that cracks initiate after a strain of 0.1 .

\section{References}

[1] U. Beuscher, S.J.C. Cleghorn, W.B. Johnson, International Journal of Energy Research 29 (2005) 1103-1112.

[2] S. Cleghorn, J. Kolde, W. Liu, Catalyst coated composites membranes, in: V. Wolf, L. Arnold, G. Hubert (Eds.), Handbook of Fuel Cells - Fundamentals, Technology and Applications, John Wiley \& Sons, Ltd, 2003.

[3] J. Xie, D.L. Wood III, D.M. Wayne, T.A. Zawodzinski, P. Atanassov, R.L. Borup, Journal of the Electrochemical Society 152 (2005) 104-113.

[4] S. Kundu, M.W. Fowler, L.C. Simon, S. Grot, Journal of Power Sources 157 (2006) 650-656.

[5] P. Rama, R. Chen, J. Andrews, Proceedings of the Institution of Mechanical Engineers, Part A: Journal of Power and Energy 222 (2008) 421-441.

[6] M. Crum, W. Liu, Effective Testing Matrix for Studying Membrane Durability in PEM Fuel Cells: Part 2, in: Mechanical Durability and
Combined Mechanical and Chemical Durability, vol. 3, Electrochemical Society Inc., Pennington, NJ, United States, Cancun, Mexico, 2006, pp. $541-550$.

[7] D.A. Dillard, M. Budinski, Y.-H. Lai, C. Gittleman, Tear resistance of proton exchange membranes, in: Proceedings of the 3rd International Conference on Fuel Cell Science, Engineering, and Technology, 2005, Ypsilanti, MI, United States, 2005, pp. 153-159.

[8] W. Liu, K. Ruth, G. Rusch, Journal of New Material for Electrochemical Systems 4 (2001) 227-232.

[9] Y.-H. Lai, C.S. Gittleman, C.K. Mittelsteadt, D.A. Dillard, in: Proceedings of the 3rd International Conference on Fuel Cell Science, Engineering, and Technology, Ypsilanti, MI, United States, 2005, pp. 161-167.

[10] V. Stanic, M. Hoberecht, Mechanism of Pin-hole Formation in Membrane Electrode Assemblies for PEM Fuel Cells, Electrochemical Society Inc, 2004, p. 1891.

[11] A. Kusoglu, A.M. Karlsson, M.H. Santare, S. Cleghorn, W.B. Johnson, Journal of Power Sources 161 (2006) 987-996.

[12] Y. Tang, M.H. Santare, A.M. Karlsson, S. Cleghorn, W.B. Johnson, Journal of Fuel Cell Science and Technology 3 (2006) 119-124.

[13] M.F. Mathias, R. Makharia, H.A. Gasteiger, J.J. Conley, T.J. Fuller, C.J. Gittleman, S.S. Kocha, D.P. Miller, C.K. Mittelsteadt, T. Xie, S.G. Van, P.T. Yu, Electrochemical Society Interface 14 (2005) 24-35.

[14] A.Z. Webber, J. Newman, AIChE Journal 50 (2004) 3215-3226.

[15] Z. Lu, M. Lugo, M.H. Santare, A.M. Karlsson, F.C. Busby, P. Walsh, Journal of Power Sources 214 (2012) 130-136.

[16] Z. Lu, C. Kim, A.M. Karlsson, J.C. Cross, M.H. Santare, Journal of Power Sources 196 (2011) 4646-4654.

[17] A. Kusoglu, A.M. Karlsson, M.H. Santare, S. Cleghorn, W.B. Johnson, Journal of Power Sources 170 (2007) 345-358.

[18] A. Kusoglu, A.M. Karlsson, M.H. Santare, S. Cleghorn, W.B. Johnson, ECS Transactions 16 (2008) 551-561.

[19] Y. Tang, A. Kusoglu, A.M. Karlsson, M.H. Santare, S. Cleghorn, W.B. Johnson, Journal of Power Sources 175 (2008) 817-825.

[20] X. Huang, R. Solasi, Y. Zou, M. Feshler, K. Reifsnider, D. Condit, S. Burlatsky, T. Madden, Journal of Polymer Science Part B: Polymer Physics 44 (2006) 2346-2357.

[21] M.N. Silberstein, P.V. Pillai, M.C. Boyce, Polymer 52 (2011) 529-539.

[22] M.N. .Silberstein, M.C. Boyce, Journal of Power Sources 195 (2010) 56925706.

[23] R. Solasi, Y. Zou, X. Huang, K. Reifsnider, Mechanics of Time-Dependent Materials 12 (2008) 15-30.

[24] Y.H. Lai, C.K. Mittelsteadt, C.S. Gittleman, D.A. Dillard, Journal of Fuel Cell Science and Technology 6 (2009), 021002-021002-13.

[25] N.S. Khattra, A.M. Karlsson, M.H. Santare, P. Walsh, F.C. Busby, Journal of Power Sources 214 (2012) 365-376.

[26] ABAQU ABAQUS, ABAQUS Inc, 2009.

[27] H.P. Yin, A. Ehrlacher, Mechanics of Materials 23 (1996) 287-294.

[28] W. Ramberg, W.R. Osgood, Description of Stress-strain Curves by Three Parameters. Technical Note No. 902, National Advisory Committee For Aeronautics, Washington DC, 1943. 